\title{
O corpo-produto perfeito: \\ Estratégias discursivas de beleza da revista Nova
}

Anelise Rublescki

Doutoranda em Comunicação e Informação da Universidade Federal do Rio Grande do Sul mestre em Comunicação/Ciência da Informação pelo convênio Universidade Federal do Rio de Janeiro/CNPq/Ibict, jornalista. Bolsista Capes.

\section{Resumo}

Este artigo considera o jornalismo como um lugar discursivo, um campo de produção e circulação de sentidos, estruturado por um contrato de leitura entre o enunciador e o leitor. Através da perspectiva da Análise de Discurso Francesa, evidencia as estratégias discursivas da revista Nova, uma publicação que potencializa a produção de sentidos em torno de um padrão estético inacessível para a maioria das mulheres.

Palavras-Chave: Jornalismo, análise do discurso, revista Nova, estratégias discursivas.

\section{Abstract}

This article considers journalism as discourse, a field of production and circulation of meaning, structured by a reading contract between the enunciator and the reader. Through the perspective of French Discourse Analysis, highlights the discursive strategies of Nova, a magazine that enhances the production of meaning around an aesthetic standard that is inaccessible to most women.

Keywords: Journalism, discourse analysis, Nova magazine, discoursive strategies.

O conceito de belo, com padrões estéticos definidos, sempre esteve presente nas mais diversas civilizações, sendo um dos traços constitutivos de uma sociedade em dado momento histórico e contexto social. Nas últimas décadas, a mídia desempenha papel essencial na divulgação e reprodução daquilo que é tido como modelo de corpo "ideal”, que, a partir dos anos 1990, mostra-se como magro, belo, saudável, jovem e com músculos definidos. A mídia produz discursos e, assim, sutilmente ou não, vende idéias, produtos, padrões e estilos.

São discursos que agregam variadas estratégias discursivas, inseridas numa situação comunicacional específica (tempo, lugar, circunstância), determinadas por características do contexto, aqui entendido como as condições sócio-históricas de produção e recepção, próprias do campo dos media e, neste artigo, do Jornalismo (1).

O conceito de linguagem como ação - e não apenas como mero instrumento de comunicação - é a base de correntes de estudos diversas, como a Pragmática, a Teoria dos Enunciados, a Semiótica, a Hermenêutica e da Análise do Discurso (AD), em suas variantes. 
A Análise do Discurso é uma ciência que situa o seu objeto - o discurso- nos campos das relações entre o lingüístico e o sócio-histórico, buscando, no interior deste campo, as determinações sociais, políticas e culturais dos processos de construção do sentido" (MARIANI, 1999: 107).

A partir do pressuposto da linguagem como mecanismo de interação, afirma-se, então, que são discursos de produção e circulação de sentidos, onde o analista procura descrever, evidenciar e avaliar criticamente como os produtos culturais - concebidos como textos na $\mathrm{AD}$ - funcionam como processo comunicacional.

O objetivo do presente trabalho é a análise do discurso da revista Nova em torno do "ideal de beleza", com o mapeamento das estratégias discursivas adotadas pela revista nas matérias que abordam estética, saúde e beleza, através da Análise do Discurso de linha francesa (2).

\section{Discurso e jornalismo}

As teorias e metodologias que sustentam a Análise do Discurso vêm sendo desenvolvidas a partir de pressupostos da Lingüística, buscando correlacionar a língua com o contexto histórico, visto que atuam juntos na produção de sentidos por um sujeito discursivo que funciona pelo inconsciente e pela ideologia (ORLANDI, 2001).

Seu objeto empírico constitui-se nos produtos culturais produzidos por eventos comunicacionais, especialmente textos. É "na superfície dos textos que podem ser encontradas as pistas ou marcas deixadas pelos processos sociais de produção dos sentidos que o analista vai interpretar" (PINTO, 1999: 22). A AD francesa representa uma abordagem do estudo do texto além da linearidade, a partir de um conjunto de conceitos inaugurados por Michel Pêcheux, na década de 1970, partindo do pressuposto de que não há discurso sem sujeitos e, tampouco, sujeito sem ideologia (3). Nesse artigo, considera-se o Jornalismo - um gênero dentro do tipo midiático (MAINGUENEAU, 2004) - como prática discursiva. Um "discurso dialógico, polifônico, opaco, ao mesmo tempo efeito e produtor de sentidos, elaborado segundo condições de produção e rotinas particulares" (BENETTI, 2007: 107).

Para a AD, todo discurso é dialógico, porque existe somente na relação entre discursos. Bakhtin (1992, 1979) aborda os enunciados como um composto de pontos de vista, visões de mundo, informações anteriores ao próprio discurso e a essa interação e/ou confronto denomina dialogismo, um princípio constitutivo da linguagem. O dialogismo e o interdiscurso operam como fonte de sentidos, onde um dizer remete a uma filiação de dizeres e a uma historicidade.

Orlandi aponta que o interdiscurso é a memória do discurso, ou seja, tudo aquilo que já foi dito antes, noutro lugar, e que retorna sob a forma do pré-construído: 
[...] é o que chamamos memória discursiva: o saber discursivo que torna possível todo dizer e que retorna sob a forma do pré-construído, o já-dito que está na base do dizível [...] o interdiscurso disponibiliza dizeres que afetam o modo como o sujeito significa em uma situação dada (ORLANDI, 2005: 31).

A multiplicidade das imagens mentais que um discurso é capaz de sugerir é um dos mais importantes fatores da pluralidade de interpretações a que se presta cada dizer. Diz-se que o jornalismo é opaco justamente pela multiplicidade de discursos potencialmente presentes, pela pluralidade de interpretações e leituras possíveis. Para a $\mathrm{AD}$, um discurso é produzido "não apenas pelo autor da fala (4) ou enunciador, mas também pelo sujeito que lê (5)" (BENETTI, 2007: 108).

O discurso jornalístico está inscrito em uma dinâmica social que já se mostra na sua produção: depende de quem enuncia e do lugar de fala desse enunciador. Não é qualquer sujeito que pode enunciar nesse lugar; ele precisa ser dotado de uma autoridade enunciativa. O capital social do Jornalismo é a credibilidade (BERGER, 1998), construída junto aos leitores intrinsecamente associada com a "vontade de verdade" (FOUCAULT, 1999) (6). Os discursos jornalísticos tornam-se expressões do que é verdadeiro; e é com eles, vale dizer, que construímos os nossos modos de compreender e ver o mundo (RESENDE, 2007: 3).

Uma estratégia utilizada no processo de enunciação jornalística, que reforça o lugar de fala autorizado é o uso da terceira pessoa, a forma verbal da não pessoa. Essa prática propicia ao discurso jornalístico, bem como ao discurso científico, uma estratégia de universalidade referencial dos enunciados, uma credibilidade da narração dos fatos a partir do lugar de fala do enunciador: "quem fala e de onde fala são critérios absolutamente relevantes e definidores do que é ou deixa de ser verdade" (idem: 3).

O Jornalismo é um discurso onde os interlocutores já foram previamente reconhecidos como tendo o direito de falar, no qual os lugares de fala (quem fala e para quem fala), as circunstâncias, o contexto, e a forma (como fala) já foram autorizados, em um contrato de leitura (VERON, 1984) implícito.

\section{Contrato de leitura}

A noção de contrato de leitura (VERÓN, 1984) ou de contrato de comunicação (CHARAUDEAU, 2006) entende o contrato como um dispositivo de enunciação onde se caracteriza a relação entre suporte, seu público e as estratégias utilizadas na construção do discurso. Esse acordo - implícito, tácito - deve permitir ao leitor identificar o posicionamento por parte do enunciador e o gênero de leitura que faz.

No caso do jornalismo, falamos de um acordo entre o jornalista e o leitor sobre o que é o jornalismo, o que pode ser dito (e o que não pode ser dito), o lugar reservado ao leitor, o papel que o jornalista deve exercer e o tipo de informação que deve entregar (BENETTI, 2007: 2). 
Os textos jornalísticos mobilizam diferentes formas de enunciação e de organização dos enunciados. Pinto, pesquisador especialista em semiologia, lingüística e análise de discursos, ao sistematizar os conceitos da análise de discursos das principais correntes da tradição francesa e anglo-americana, salienta que a AD "não se interessa tanto pelo que o texto diz ou mostra, pois não é uma interpretação semântica de conteúdo, mas sim em como e porque diz e mostra" (PINTO, 1999: 23). Para o autor, do ponto de vista de uma prática analítica, os modos de dizer podem ser resumidos e explicitados em modos de mostrar (uso referencial do discurso, que possibilita anunciar, argumentar, demonstrar e descrever), modos de interagir (modos como são construídas as identidades e relações sociais assumidas pelos participantes no processo comunicacional) e modos de seduzir (uso da linguagem na busca do consenso, pelo qual se distribuem os afetos positivos e negativos associados ao universo de discurso em jogo). Todas essas formas de enunciados foram encontradas na análise de discurso da revista Nova no corpus analisado.

Um contrato de leitura jornalístico abrange todos os aspectos envolvidos no discurso, desde a construção do suporte (ele mesmo já um discurso, visto ser um contexto) até a ligação com o leitor: as matérias (7), os dispositivos de chamada (títulos, subtítulos), a relação texto/imagem, tipos de percursos propostos ao leitor, modalidades de diagramação e outras dimensões que podem contribuir para definir o modo específico pelo qual o suporte constrói a ligação com o leitor, tornando-se um espaço de circulação e produção de sentidos.

\section{As revistas femininas}

A evolução da mulher enquanto leitora perpassa momentos de total proibição até os dias atuais, em que as publicações femininas se multiplicam nas bancas. Durante esse período, a mulher emancipou-se, conquistou o mercado de trabalho, viu surgir uma nova sociedade, com novas questões, outros perfis de pautas editoriais, novas publicações que se adaptaram e seguem se transformando na busca de suas leitoras. Entre as revistas, a segmentação por assunto e perfil sócio-econômico de público faz parte da própria essência do veículo e é um dos principais fatores que permitiram o crescimento do segmento no mercado editorial brasileiro.

Para Scalzo, uma revista é um signo distintivo, uma marca de pertencimento a um grupo:

As revistas são objetos queridos, fáceis de carregar e colecionar. São também boas de recortar, copiar: vestidos, decorações, arrumações de mesa, receitas de bolo, cortes de cabelo, aulas, pesquisas de escola, opiniões, explicações. Revista é também um encontro, entre um editor e um leitor, um contato que se estabelece, um fio invisível que une um grupo de pessoas e, nesse sentido, ajuda a construir identidades, ou seja, cria identificações, dá sensação de pertencer a um determinado grupo. Entre garotas, por exemplo, sabe-se que quem lê Capricho é diferente de quem não a lê. Não é à toa que leitores gostam de andar abraçados com suas revistas para apontar seu pertencimento (SCALZO, 2004: 12).

E a autora vai mais além e nos diz: 
Uma revista é um veículo de comunicação, um produto, um negócio, uma marca, um objeto, um conjunto de serviços, uma mistura de jornalismo e entretenimento. Nenhuma das definições acima está errada, mas também nenhuma delas abrange completamente o universo que envolve uma revista e seus leitores [...] Revista é também um encontro entre um editor e um leitor, um contato que se estabelece, um fio invisível que une um grupo de pessoas [...] É na revista segmentada, geralmente mensal, que de fato se conhece cada leitor, sabe-se exatamente com quem se está falando (SCALZO, 2004: 12-14).

A revista Nova, como será demonstrado a seguir, tem um modo bem particular e pessoal de dialogar com suas leitoras.

\section{Nova}

Nova (8) foi lançada em setembro de 1973, sendo uma publicação mensal da Editora Abril, com circulação média de 212 mil exemplares, entre vendas avulsas e assinantes. Segundo o grupo Abril, 84\% dos leitores são mulheres, $46 \%$ pertencem à classe sócio-econômica $\mathrm{B}$ e a faixa etária predominante é de os leitores dos 25-39 anos (37\%) (9).

O conteúdo editorial desenvolve-se nos eixos temáticos Amor/Sexo - Beleza/Saúde, Vida/Trabalho Moda/Estilo - Gente Famosa, sendo que as matérias de capa costumam contemplar todos os eixos. Sob as denominações de "É quente, é NOVA!" e "Mais" encontram-se agrupadas as colunas mensais de Nova, as seções de dicas e as reportagens permanentes (como "Segredo de Estrela" e "Teste Drive", por exemplo), a charge Radical Chic, sempre na última página, o "Notícias da Redação", a Opinião Livre (cartas de leitores) e o horóscopo.

A análise contemplou as edições de julho a outubro de 2007 (edições 406 a 409). Foram consideradas todas as matérias que direta ou indiretamente se relacionavam com beleza, incluindo comportamento, estética, dietas, exercícios, cirurgias ou tratamentos médicos, conceitos de "boa forma", produtos e dicas, independente da sua localização na estrutura redacional de Nova. As imagens ilustrativas também foram consideradas.

Texto e imagem em Nova têm pesos equivalentes, sendo ora o texto ilustrado pela fotografia, ora a imagem sendo o discurso propriamente dito, apenas apoiado pelo texto. As reportagens mais longas da revista têm seis páginas, sendo a média de quatro a duas páginas, sempre com a presença expressiva de fotos. Em algumas seções fixas, como "Repórter de Moda" (que abordaremos oportunamente), a imagem é a reportagem. Observa-se que em termos visuais, a revista passa um enquadramento intencional pouco variável, não apenas do conteúdo interno, mas também das capas, que já caracterizam uma primeira estratégia discursiva da publicação: 


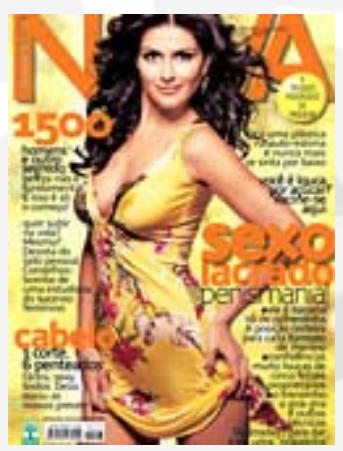

julho 2007

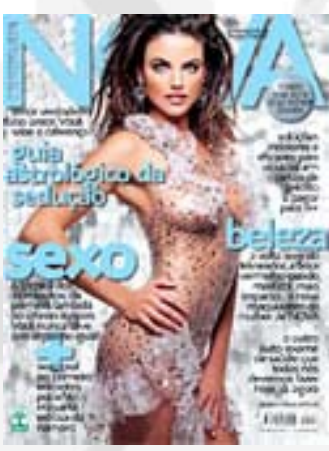

agosto 2007

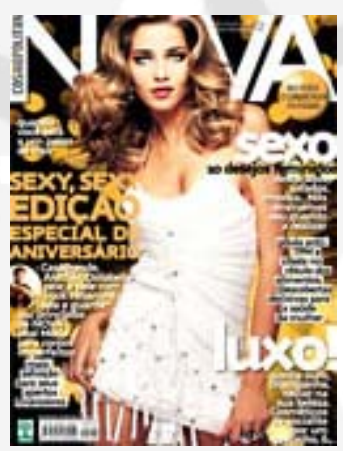

setembro 2007

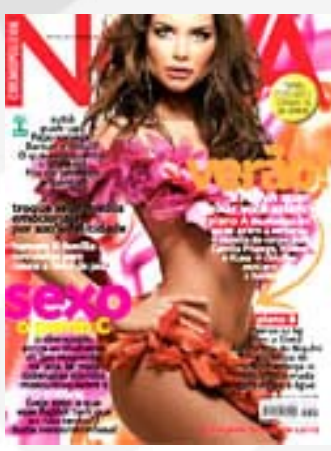

outubro 2007

As capas apresentam uma "musa" famosa, sumariamente vestida, orgulhosa do seu corpo, ousada em seu decote, sensualmente exposta. As fotos demonstram uma mulher segura, desinibida e de olhar firme, sentido criado pelo olhar de frente, que "sustenta" o olhar da leitora. Além das fotos, há todo um jogo de cores nas capas de Nova: contraste do fundo com o nome da publicação e destaque nas palavras-chave dos enunciados. "O uso das cores dirige o olhar do leitor mais pelo sentimento do que pela razão" (BUITONI, 1981: 25).

Dois outros tipos de imagens se fazem presentes na revista: os anúncios publicitários e as imagens publicitárias. Para fins desse trabalho consideramos anúncios publicitários as mensagens pagas, veiculadas sob a forma de uma marca comercial. Do corpus analisado (760 páginas no somatório das quatro edições), 35\% se enquadram nessa categoria, sendo 26 páginas da própria Abril, divulgando outras revistas ou projetos apoiados pela Editora. O discurso dos anúncios publicitários não era objetivo do presente trabalho, embora a publicidade seja uma situação comunicacional rica para a formação de sentidos.

As imagens publicitárias (presentes em 8,5\% do corpus analisado) desvelam-se de duas formas na revista em análise:

a) Imagens publicitárias que apresentam produtos cosméticos, com indicações de uso, fabricantes e preços veiculadas nas seções editoriais, em meio a textos informativos. (10)

b) Fotografia editorial, como na seção Repórter de Moda, onde as modelos são produzidas com produtos cedidos para esse fim, com marca e preço fornecidos no rodapé ou nas legendas das fotos e o endereço e/ou telefone da loja na última página da revista. A mesma forma de produção aparece também em outras seções que buscam igualmente criar estilo. 


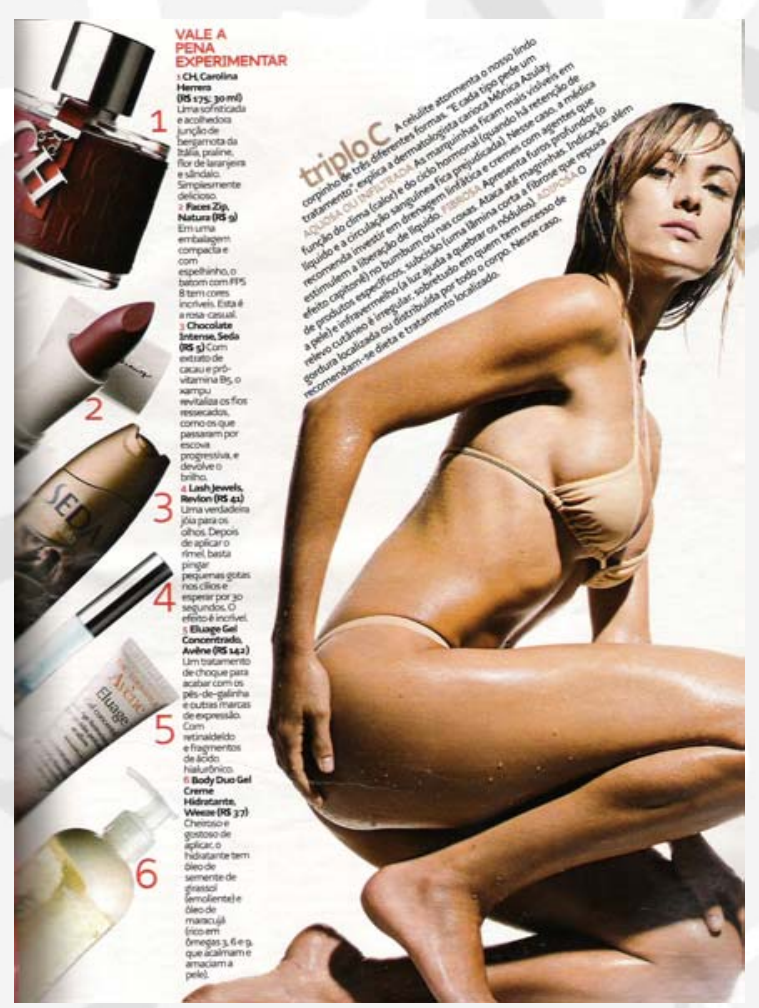

NOVA, Repórter de Beleza, ed. 409, p. 37

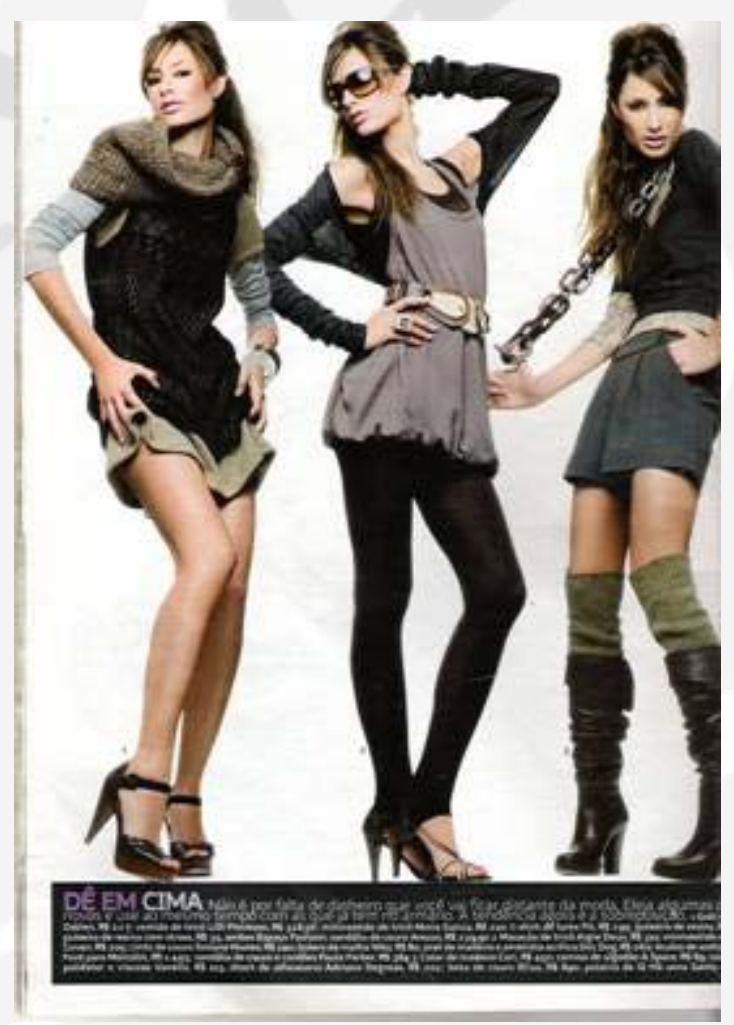

NOVA, Repórter de Moda, ed. 406, p. 36

No primeiro exemplo - seção Repórter de Beleza há uma fronteira tênue entre publicidade e jornalismo, visto que o texto "Triplo C" é baseado na opinião de uma médica (o discurso técnico-científico será abordado oportunamente). Ao lado, embora não se destinem à celulite (assunto central na matéria Triplo C), há produtos indicados para beleza, com o nome do fabricante e preço de mercado. Esse é um discurso que tanto informa quanto induz ao consumo; além de se confundir com a publicidade ao divulgar fabricantes e produtos específicos (11).

No segundo exemplo, o texto do rodapé fornece fabricante e preço dos produtos das peças e acessórios utilizados pela modelo. Veicula a tendência de moda, dialogando com o desejo da leitora. Sua função é formar opinião, introduzindo novos padrões de cultura e imagem. Vale ressaltar que todas as imagens no corpus da pesquisa enquadravam-se rigorosamente no padrão estético alto, magro, definido. A reiteração da estética "perfeita” já uma das estratégias discursivas recorrentes em Nova.

\section{Estratégias textuais e discursivas}

Como já dito, o discurso jornalístico depende diretamente de quem enuncia e do lugar de fala desse enunciador. Na revista Nova falam o leitor (não possui meio especializado), os especialistas (meio técnicocientífico), os famosos (meio imagético) e o jornalista. Ao emitir o discurso, o jornalista-autor o enuncia 
também de acordo com as rotinas produtivas das redações, com as práticas jornalísticas e o lugar de fala da instituição a qual pertence (TUSCHMAN, 1973; BREED, 1999).

Uma das estratégias discursivas de Nova ao se constituir como um lugar de dizer institucional, é adotar uma "personalidade feminina". Para além de abordar temas que interessam a sua leitora virtual, Nova enuncia como se ela própria fosse uma mulher, facilitando a identificação das leitoras:

“90 razões por que adoramos os homens" (grifo nosso - edição 407, agosto 2007, p. 83).

"Com vocês, o regulamento interno da confraria de mulheres mais poderosas do planeta. Bem-vinda ao clube, irmã!" (grifo nosso - edição 408, setembro 2007, p. 164).

A informalidade, como nesse último exemplo, é outra estratégia discursiva de Nova, que induz proximidade, cumplicidade. Em uma conversa próxima, entre amigas, as idéias parecem simples, cotidianas, naturais. “A razão não se arma para uma conversa de amiga” (BUITONI, 1981: 25).

A "conversa" informal da revista estrutura-se sobre dois eixos, aparentemente antagônicos, mas que se mostram pelo sentido que induzem. Por um lado, Nova valida os sentimentos/dúvidas/frustrações da leitora com enunciados generalizantes:

"Que a correria no trabalho pega todas nós pelo pé mais cedo ou mais tarde, é fato" (grifo nosso edição 406, julho 2007, p. 94).

“10 entre 12 garotas se enchem de felicidade inexplicável ao entrar numa calça 38 - e se sentem culpadas ao ter de usar 40 ou mais.” (grifo nosso - edição 408, setembro 2007, p. 125).

e, ao mesmo tempo, pratica um discurso personalizante:

“Esta novidade é para você: lipoaspiração superficial para celulite.” (grifo nosso - edição 409, outubro 2007, p. 165).

“[...] um menu com alimentos do cotidiano de uma mulher agitada, que trabalha... como você! (grifo nosso edição 409, outubro 2007, p. 162).

Numa linguagem muito próxima a da publicitária, os textos em Nova são persuasivos, aconselhando as leitoras permanentemente sobre o que fazer. Essa função conotativa da linguagem é um dos traços marcantes do corpus analisado. Evidencia-se pelo uso do pronome de tratamento você, vocativos e pela forma verbal do imperativo. A fragmentação do enunciado também é uma estratégia discursiva, pois faz com que o leitor se insira nos interstícios da frase e complete o sentido. 
“[...]Sendo assim, não dê moleza.” (grifo nosso - edição 407, agosto 2007, p. 37).

Transforme gordura em água - (grifo nosso - edição 409, outubro 2007, p. 165).

Enunciados como o "Transforme gordura em água" propiciam também um apelo à curiosidade de quem os lê. "Como" é o sentido buscado, que tende a canalizar para a leitura integral da matéria. É uma estratégia freqüente do discurso jornalístico e se mostra especialmente nos títulos, subtítulos, olhos e chamadas de capa. Os trechos a seguir apresentam outros exemplos da curiosidade como prática discursiva em Nova:

"Perder 12 quilos em três meses comendo delícias como sorvete, pizza e até pão francês? A gente revela [...]" (grifo nosso - edição 409, outubro 2007, p. 162).

"Nem só de musculação vivem as donas de curvas incríveis" (referindo-se a atriz Daniele Suzuki, em texto ilustrado com foto - edição 408, setembro 2007, p. 90).

Neste exemplo, além da "curiosidade", Nova utiliza um discurso que se mostra de acordo com o mundo artístico/imagético, através de pessoas que estão em evidência na televisão, nos esportes, nas novelas, nas passarelas. É um discurso onde as funções de sedução e interação estão mais presentes, através do mundo da fama e do sucesso.

No corpus analisado, esse tipo de matéria sempre é ilustrada com fotos, visto que a ênfase do sentido recai sobre a imagem do "corpo ideal". Como exemplo, citamos a reportagem "Corpos Estrelados" (edição 409, outubro 2007, p. 160), onde a revista "releva os segredos dos corpos mais comentados do País" com Ildi Silva, Camila Pitanga, Priscila Fantin e Xuxa, incluindo a dieta, o programa de exercícios e as recomendações dos médicos que cuidam dos corpos e da pele das atrizes. A matéria é ilustrada com grandes fotos das "belas", devidamente produzidas e clicadas.

Em diversos discursos de Nova, outras estratégias discursivas se somam ao imagético:

"Pernas, pra que te quero! [...] grossas, bem torneadas e firmes pra marmanjo nenhum botar defeito. [...], explica Marcello Barbosa, personal trainer de beldades como Angélica e Grazi Massafera. [...] com uma foto da apresentadora Angélica, de biquíni” (grifo nosso - edição 408, setembro 2007, p. 54).

Segundo a médica ortomolecular carioca Heloísa Rocha, responsável pela boa forma de Deborah Secco e Priscila Fantin, açúcar demais também tende a provocar [...] (grifo nosso - edição 406, julho 2007, p. 95).

Os dois enunciados acima envolvem diversas percepções de sentidos possíveis. O discurso dos especialistas se mostra com base em um referente técnico/especializado, já que personal trainer é um profissional tecnicamente capacitado para gerenciar a boa forma; a médica é a autoridade. Há também o 
interesse em divulgar um profissional específico, destacando que é um profissional reconhecido, pois trata-se da médica/do personal das estrelas de televisão, acrescentando mais um elemento à inquestionável ciência, e permitindo a leitura de que, "se cuidam de celebridades, devem ser ótimos". Por último, mas especialmente relevante, a creditação. O nome dos profissionais dá ao discurso credibilidade e sentido de real, pois não se trata de um personagem fictício, mas de alguém com um lugar de fala explicitado.

O uso de fontes é, obviamente, comum e desejável no jornalismo. Diversas outras formas de validação da informação foram registradas durante a análise do material. Nova utiliza freqüentemente resultados de pesquisas em universidades (destaque para as americanas), com nomeação do centro de pesquisa e do médico responsável. Publicações são usualmente referenciadas, quer como sugestão de leitura, quer com transcrição de um trecho para validar uma informação. Outra estratégia de creditação refere-se aos relatos de experiência, tanto de leitoras, quanto de repórteres, que testam produtos, técnicas, enfrentam desafios e compartilham depois sua vivência, através do seu lugar de fala. No caso de relato por parte de leitoras, a foto faz o papel de creditação/validação.

A leitora de Nova ocupa o lugar de fala nas páginas da revista em quatro situações: cartas à redação (seção "Opinião Livre"), enquetes (pelo site, onde algumas respostas são selecionadas pela redação para publicação na edição impressa do mês seguinte), depoimentos/relatos já mencionados e através do envio de perguntas à redação. No material analisado, as perguntas giravam em torno de alimentação/estética e as respostas (nutricionista/médico respectivamente nos exemplos abaixo) são dois outros exemplos de creditação pela fala competente. Exemplos de perguntas de leitoras:

Como monto meu cardápio para ser jovem para sempre? (edição 408, setembro 2007, p. 86).

Tenho uma dúvida daquelas: comer arroz todos os dias engorda? (edição 407, agosto 2007, p. 82).

O interdiscurso é outra estratégia muito presente no corpus analisado. Em Nova, o interdiscurso aparece de duas formas, especialmente quando associado aos novos tratamentos.

Do manequim 44 para o 40- [...] Velasmooth promete revolucionar os tratamentos estéticos. E não é para menos. Ele reúne três técnicas potentes (massagem a vácuo, radiofreqüência e infravermelho) em um só aparelho. A vantagem? Em uma sessão você alcança o que pediria três visitas à clínica (grifo nosso - edição 409, outubro 2007, p. 164).

Se você sofre só de pensar em levar choquinhos, a endermologia vibratória pode ser a solução para sua celulite. “A técnica é indolor e não deixa marcas”, diz a dermatologista carioca Karla Assed. Dá para fazer e ir direto para a praia! (grifo nosso - edição 409, outubro 2007, p. 165). 
No primeiro exemplo o discurso remete a otimização de resultados e de tempo por serem três tratamentos em um. Nova faz a articulação de sentidos interdiscursivos para a leitora, explicitando claramente que “em uma sessão se obtém o resultado de três", referindo-se a tratamentos não tão modernos, presumivelmente já conhecidos pela leitora. No segundo exemplo, a leitora não precisa mais sofrer para terminar com a celulite em tratamentos com aparelhos. Hoje tudo é tão rápido e indolor que nem repouso mais se faz necessário. Nesse exemplo, o discurso pressupõe que as leitoras saibam que os tratamentos anteriores eram por corrente elétrica, dolorosos, que tinham um pós-procedimento demorado. Nesse caso, o discurso de Nova apresenta-se marcado pela pressuposição.

Enunciados com discursos de reforço à auto-estima, com frases similares às técnicas de auto-ajuda foram encontrados nas quatro edições analisadas: “Quem se gosta se cuida” (edição 407, agosto 2007, p. 82). "Ficar de bem com o corpo que você tem" (edição 408, setembro 2007, p. 166), "Não ser escrava da beleza" (edição 406, julho 2007, p.94), “Querer é poder” (edição 408, setembro 2007, p. 166) são alguns exemplos.

Mas igualmente freqüente é encontrar nas páginas de Nova enunciados que parecem investir na confiança e auto-estima da leitora, mas que reforçam, de maneira sutil, a culpa por estar fora dos padrões estéticos corporais ou não agir de forma "correta" para manter-se em forma. Alguns exemplos:

Sentir-se gostosa, mesmo com uns quilinhos a mais (grifo nosso - edição 408, setembro 2007, p. 166).

Comer sem culpa a caixa toda de trufas, que ninguém é de ferro e segunda-feiraestá logo aí para começar a dieta (grifo nosso - edição 408, setembro 2007, p. 166).

Dizer não! às fôrmas, rótulos e modelos de beleza inatingíveis [...] mas defender com unhas e dentes o patrimônio que a natureza lhe deu, usando e abusando de cremes, tratamentos e até truques sujos, em caso de emergência (do tipo calcinha levanta-bumbum) (grifo nosso - edição 408, setembro 2007, p. 164).

O importante, evidencia o exemplo, é a beleza, mesmo se conseguida com artifícios ("truques sujos"): Nova prescreve as soluções e ensina sua leitora a ser uma versão "perfeita" de si mesma, porque o jornalismo prescritivo/normativo é uma das estratégias discursivas mais utilizadas na revista. Manifesta-se ao longo das matérias e também se faz presente na forma de guias que ensinam à leitora os sete truques de maquiagem para ser irresistível, cinco exercícios para barriguinha chapada, dietas para a semana, etc. Discursos na versão “manual passo-a-passo" para construção do corpo imagético. Alguns exemplos:

Para a maioria das mulheres é simplesmente impossível viver sem o açúcar e, para a maioria dos médicos, ele pode desencadear várias doenças. Será que não existe meio-termo? Sim, e nós vamos mostrar como se entregar aos doces prazeres sem colocar a saúde - e o peso - em risco (grifo nosso - edição 406, julho 2007, p. 96). 
Nova quer deixar você assim: Plano A - do manequim 44 ao 40 em 4 semanas, + receita do corpaço de Camila Pitanga, Aline e Xuxa + celulite zero em duas horas.[...][a chamada também oferecia um Plano B] (grifo nosso - edição 406, julho 2007, p. 94).

A justificativa para essa abordagem está nos dizeres da própria revista: "nós [as diretoras de Nova] juramos ter sempre à mão respostas para as perguntas, orientação em caso de dúvidas, norte para quem está perdida" (NOVA, edição 408, setembro 2007, p. 165).

\section{Considerações finais}

A linha editorial de Nova reflete uma versão singular da realidade, moldada com presumíveis valores do público-alvo, o leitor virtual. Para além das informações nela contidas, a revista estabelece um diálogo com as leitoras, assumindo um papel de comentarista dos modos de viver, tornando-se, assim, um documento da cultura de uma época, de um grupo de pessoas.

Os estereótipos detectados na representação da mulher pela revista sinalizam que a leitora deve ser tão bonita quanto as celebridades, com definição de padrões de beleza imagéticos, praticamente inalcançáveis pela maioria das mulheres. Nova expressa claramente o padrão estético desejável, os tratamentos possíveis, as técnicas mais modernas, os cosméticos indicados, os truques para contornar a natureza a qualquer preço. “Querer é poder” afirma Nova (NOVA, edição 408, setembro 2007, p. 166).

A revista, que se posiciona como se fosse outra mulher em conversa amigável, utiliza uma linguagem didática, coloquial, freqüentemente próxima a dos livros de auto-ajuda. Associados a esse posicionamento e estratégia discursiva, a revista induz aos sentidos de identificação, validação de sentimentos, proximidade, cumplicidade, personalização, curiosidade. Paralelamente, ainda que de forma sutil, induz a culpa das leitoras que se encontram fora do padrão estético corporal idealizado ou que não agem de acordo com a ditadura da boa forma. Se "querer é poder" cabe à leitora "apenas" querer.

Com reportagens tipo passo-a-passo, o jornalismo de Nova é prescritivo/normativo. O contrato de leitura entre a revista e a leitora centra-se na lógica "você lê/nós lhe dizemos o quê e como fazer".

De todas as estratégias discursivas utilizadas, a mais freqüente é a reiteração. Reiteração da estética corporal "perfeita", que se mostra, interage e seduz não apenas através das reportagens/pautas recorrentes, mas, sobretudo, com a reiteração do imagético (atrizes/modelos), associando o corpo-produto ao sucesso e à fama. Ao longo das quatro edições analisadas, não havia uma única foto fora do padrão belo-cuidado-magro. Como dito no início do artigo, com uma lógica simbólico-mercadológica, Nova produz discursos e sentidos que se traduzem em idéias, padrões e estilos. 


\section{Referências}

BAKHTIN, Mikhail. "Os gêneros do discurso". In: BAKHTIN, M. Estética da criação verbal. São Paulo: Martins Fontes, 1997.

. Marxismo e Filosofia da Linguagem São Paulo: Hucitec, 1992.

BENETTI, Marcia. “A ironia como estratégia discursiva da revista Veja”. In: XVI Compós, 2007, Curitiba. Anais do XVI Encontro Anual da Associação Nacional dos Programas de Pós-Graduação em Comunicação. Compós: Curitiba, 2007. v. 1. p. 1-10.

. Análise do Discurso em Jornalismo: estudo de vozes e sentidos. In: LAGO, Cláudia; BENETTI, Marcia. (Org.). Metodologia de Pesquisa em Jornalismo. Petrópolis: Vozes, 2007, v. 1, p. 107-122.

BERGER, Christa. Campos em Confronto: a terra e o texto. Porto Alegre: Editora da Universidade/ UFRGS, 1998.

BRANDÃO, Helena H. Introdução à Análise do Discurso. Campinas: Editora da Unicamp, 1997.

BREED, Warren. “Controle social na redação: uma análise funcional.” In: TRAQUINA, Nelson (org). Jornalismo: questões, teorias e estórias. Lisboa: Veja, 1999.

BUITONI, D. Mulher de papel: a representação da mulher pela imprensa feminina brasileira. São Paulo: Loyola, 1981.

CHARAUDEAU, Patrick. Discurso das mídias. São Paulo: Contexto, 2006.

FOUCAULT, Michel. A ordem do discurso. São Paulo: Ed. Loyola, 1996.

MAINGUENEAU, Dominique. Análise de textos de comunicação. São Paulo: Cortez, 2004.

MARIANI, Bethania. "Sobre um percurso de análise do discurso jornalístico: a Revolução de 30". In: INDURSKY, Freda; FERREIRA, Maria Cristina Leandro (Org.). Os múltiplos territórios da Análise do Discurso. Porto Alegre: Sagra-Luzzatto, 1999.

PINTO, Milton José. Comunicação \& discurso: Introdução à análise de discursos. São Paulo: Hacker Editores, 1999.

ORLANDI, Eni P. Análise de discurso: Princípios \& Procedimentos. Campinas: Pontes, 2003. . Análise de discurso. São Paulo: Pontes, 2005.

RESENDE, Fernando. "O discurso jornalístico no contemporâneo: entre o velamento e produção das diferenças". In: XVI Encontro da Compós. Anais do XVI Encontro Anual da Associação Nacional dos Programas de Pós-Graduação em Comunicação. Compós: Curitiba, 2007.

SCALZO, Marília. Jornalismo de revista. São Paulo: Editora Contexto, 2004.

TUSCHMAN, Gaye. "Making news by doing work: routinizing the unexpected". In: American Journal of Sociology, v.79, n.1, 1973. 
VERÓN, Eliseo. A análise do contrato de leitura: um novo método para os estudos de posicionamento de suportes impressos. Tradução de Giovandro Marcus Ferreira e Augusto Drumond Moraes. Vitória:

Universidade Federal do Espírito Santo, 1999.

\section{Notas}

(1) Vizeu (2002) pontua que o processo de enunciação jornalística é regulamentado através de procedimentos mais generalizados e que se encontram estabelecidos em espécies de macro e micro códigos. Entre os macrocódigos, situam-se a língua, as matrizes culturais, as regras sociais, a ética e as ideologias. Já os microcódigos seriam aqueles códigos particulares estabelecidos pelas empresas de comunicação, como os manuais de redação, os valores-notícia e os demais critérios de noticiabilidade, manejados e mobilizados no processo de enunciação.

(2) A tradição anglo-americana, originária da Inglaterra, mas firmemente enraizada nos Estados Unidos, incorporou elementos da sociologia, da psicologia e da etnologia e prende-se mais ao empirismo (PINTO, 1999).

(3) Os conceitos de ideologia e de discurso são nucleares na AD. Para Brandão (1997), as duas grandes vertentes que vão influenciar a corrente francesa de AD são, do lado da ideologia, os conceitos de Althusser e, do lado do discurso, as idéias de Foucault. É sobre a influência dos trabalhos desses dois teóricos que Pêcheux, um dos estudiosos mais profícuos da $\mathrm{AD}$, elabora seus conceitos.

(4) "O termo "fala" não se restringe à expressão oral, mas contempla todo ato de enunciação, seja verbal ou não-verbal". (BENETTI, 2007: 108, no original).

(5) Em termos de discurso, "considera-se leitura todo ato de recepção e construção de sentidos junto a um texto enunciado por outro sujeito [...], independente da mídia de veiculação" (BENETTI, 2007: 108, no original).

(6) Foucault (1996: 8-17) examina de que maneira "a produção do discurso é ao mesmo tempo controlada, selecionada, organizada e redistribuída por certo número de procedimentos que têm por função conjurar seus poderes e perigos, dominar seu acontecimento aleatório, esquivar sua pesada e temível materialidade" (p. 8-9). Os primeiros desses procedimentos são os de exclusão, que podem ser de interdição ("não se tem o direito de dizer tudo", p. 9), de separação e rejeição ("a oposição razão e loucura", p. 10), e os de "vontade de verdade" ("oposição do verdadeiro e do falso", p. 12).

(7) Matéria "consiste em tudo o que é publicado, ou feito para ser publicado, por um jornal ou revista, incluindo texto e ilustrações. O original de qualquer notícia, artigo, crônica, nota etc., em sua forma impressa recebem o nome, genericamente, de matéria". Dicionário de Comunicação Rabaça \& Barbosa (1978).

(8) Versão brasileira da Cosmopolitan, revista feminina mais vendida no mundo, publicada em 23 idiomas, 47 edições mensais diferentes, 6 milhões de exemplares por mês, com circulação em mais de 100 países.

(9) Dados de setembro/2009. Fonte: Marplan Consolidado $2009-\mathrm{A} 10+$ anos, disponível em http://publicidade.abril.com.br/geral_circulacao_revista.php

(10) O expediente das edições analisadas traz a seguinte observação: "Nova não admite publicidade redacional".

(11) A AD, conforme abordada neste artigo, não fornece subsídios para análise de recepção. Nesse estudo, portanto, não é possível saber se o leitor considera a matéria jornalística ou como anúncio publicitário. 